\title{
O IMPACTO DA AUSÊNCIA DE SANEAMENTO PARA O RISCO DE DESLIZAMENTO, EROSÃO E INUDAÇÃO NA REGIÃO METROPOLITANA DO RECIFE
}

\author{
Daniela Josefa da Silva Nascimento ${ }^{1}$ \\ Agostinho Gomes Marinho ${ }^{2}$ \\ João Ricardo Pereira da Silva ${ }^{3}$ \\ Esley da Silva Barboza ${ }^{4}$ \\ Gustavo Gouveia Pereira da Silva ${ }^{5}$ \\ Isabel Mendes Pereira da Silva ${ }^{6}$
}

\section{RESUMO}

Esse artigo tem o objetivo de, através de um olhar mais amplo voltado para o risco de deslizamento, erosão e inundação, demonstrar a necessidade de uma relação próxima entre o saneamento básico e a redução de risco às moradias. Dados recentes informam que em toda a Região Metropolitana do Recife, apenas $30 \%$ das residências dispõem de saneamento básico. Para mudar essa realidade, o serviço público de saneamento do estado de Pernambuco firmou uma parceria pública privada (PPP), que está em implantação, para elevar o índice de cobertura do saneamento de 30 para $90 \%$, o que ajudaria também na gestão de redução do risco às moradias. A metodologia utilizada buscou apresentar exemplos de desastres e transtornos ocorridos devido à ausência ou ineficiência do conjunto de serviços descritos na Lei do Saneamento Básico. Para a ausência de abastecimento de água é apresentado um deslizamento ocorrido devido às instalações irregulares de água, provocando constantes vazamentos e o consequente deslizamento de encosta com a morte de moradores da comunidade.

Palavras-chave: Saneamento, Redução do Risco, Investimentos.

\footnotetext{
${ }^{1}$ Engenheira Civil, Professora Instituto Federal de Educação, Ciencia e Tecnologia do Ceará IFCE, Quixadá-CE, Brasil. Email: daniela.silva@ifce.edu.br

${ }^{2}$ Engenhairo Civil, Pós-graduado em Engenharia e Ciencias dos Materiais - Faculdade Unileya, Recife-Pe, Brasil, agostinhomarinho@yahoo.com.br

${ }^{3}$ Engenheira Civil, Professor de engenharia civil na Faculdade Integrada de Recife FACIPE, Recife-Pe, Brasil, eng jrps@hotmail.com

${ }^{4}$ Engenheiro civil, COMPESA, Recife, Brasil. Email: esleyb@gmail.com

${ }^{5}$ Engenheiro civil, Tecomat, Recife, Brasil. Email: gustavo@tecomat.com.br

6 Engenheira civil, Mestre, Universidade Federal de Pernambuco UFPE, Recife, Brasil, isabelmendes07@hotmail.com
} 


\title{
THE IMPACT OF THE ABSENCE OF SANITATION FOR THE RISK OF LANDSLIP, EROSION AND INUNDATION IN THE METROPOLITAN REGION OF RECIFE
}

\begin{abstract}
Basic sanitation is described by the Sanitation Law as the set of services, infrastructures and operational facilities focused on water supply, sewage, cleaning and urban drainage. These aspects are much debated and worked on in order to promote public health, improve the quality of life of the population and facilitate economic activity. The objective of this article is to demonstrate the need for a close relationship between basic sanitation and the reduction of risks to housing through a broader perspective on the risk of landslides, erosion and flooding. Recent data indicate that in the entire metropolitan region of Recife, only $30 \%$ of households have basic sanitation. To change this reality, the public sanitation service of the state of Pernambuco signed a public private partnership (PPP), which is in implementation, to increase the sanitation coverage ratio from 30 to $90 \%$, which would also help reduce of the risk to housing. The methodology used sought to present examples of disasters and disruptions that occurred due to the absence or inefficiency of the set of services described in the Basic Sanitation Law. For the lack of water supply, a slip occurs due to irregular water installations, causing constant leaks and the consequent landslide with the death of residents of the community.
\end{abstract}

Keywords: Sanitation, Risk Reduction, Investments.

Artigo Recebido em 21/12/2017 e Aceito em 12/03/2018 


\section{INTRODUÇÃO}

O agravamento de problemas socioeconômicos intensifica a demanda por ocupação de áreas que muitas vezes não são adequadas à habitação humana. Esse modo de ocupação aliada à falta de percepção de risco e à dificuldade de acesso a serviços básicos potencializam o risco de inundações e instabilização de encostas.

Neste sentido, um serviço básico importante que pode ser citado é o saneamento que é visto como necessário à garantia das boas condições de moradia e saúde da população. De acordo com a Lei 11.445/2007, saneamento é o conjunto de serviços, infraestruturas e instalações operacionais voltadas para o abastecimento de água, esgotamento sanitário, limpeza e drenagem urbana. Para uma instituição especializada como a Organização Mundial de Saúde (OMS), saneamento é o controle de todos os fatores do meio físico onde

o homem habita, que exercem ou podem exercer efeitos prejudiciais ao seu bem-estar físico, mental ou social.

É comum discutir esse conjunto de serviços com o objetivo de promover a saúde pública, melhoria da qualidade de vida da população e facilitar a atividade econômica, no entanto, com uma avaliação mais ampla dos impactos da ausência do saneamento, é possível identificar também o risco de erosão e deslizamento de encostas, e de inundação de áreas ocupadas desordenadamente. A reflexão apresentada nesse artigo demonstra exemplos de desastres e transtornos ocorridos devido à ausência ou ineficiência de cada um dos itens que compõem o conjunto de serviços descritos na Lei do Saneamento Básico.

Dados recentes informam que em toda a Região Metropolitana do Recife (RMR), apenas $30 \%$ das residências dispõem de saneamento básico. Essa 
pouca abrangência do saneamento à Região Metropolitana do Recife, contribui para a ocorrência de frequentes ocorrências de risco. Para aumentar a abrangência de atendimento dos serviços de saneamento, o serviço público de saneamento do estado de Pernambuco firmou uma parceria pública privada (PPP), que está em implantação, para elevar o índice de cobertura do saneamento de $30 \%$ para $90 \%$. O resultado dessa ampliação da cobertura de saneamento na Região Metropolitana do Recife (RMR), contribuirá significativamente para a melhoria da saúde da população, atingindo assim o seu objetivo principal, contudo vale destacar também o benefício que 0 município terá também na melhoria da gestão de redução do risco às moradias e à população.

\section{ABASTECIMENTO DE ÁGUA}

Em se tratando de abastecimento de água, o serviço público de saneamento do estado de Pernambuco possui um índice de perdas físicas, em média, de 56\% na Região Metropolitana do Recife, possuindo perdas maiores nas regiões de morros e locais habitados por população mais carente. As perdas físicas tem como principais causas dessas perdas: envelhecimento natural das infraestruturas; pressões de serviço; características do solo envolvente; frequência de passagem de cargas pessadas; obras de infraestrutura adjacentes; densidade e comprimento dos ramais; existência de programa ativo de controle de perdas e prática de políticas de reabilitação das infraestruturas.

Nas áreas de ocupações desordenadas, é comum identificar a existência de inúmeras ligações clandestinas de água, caracterizadas pela implantação de desvios de água através de tubulações postas sem planejamento e sem a correta execução. Essas tubulações, muitas vezes são acompanhadas de vazamentos que provocam a constante saturação do solo, reduzindo assim sua estabilidade. 
Revista Científica do Corpo de Bombeiros Militar de Pernambuco

Seção 1 - Artigos Técnico Científicos

Artigo publicado no Vol.04 №09 - Edição de JAN a JUN 2018 - ISSN 2359-4837(online)

Versão on-line disponível em: http://www.revistaflammae.com.

Na Figura 1 são apresentados as possíveis formas como podem ocorrer vazamentos ao longo das tubulações pertencentes a um sistema de abastecimento de água.

Figura 1. Tipos de vazamento e distribuição de volume perdido

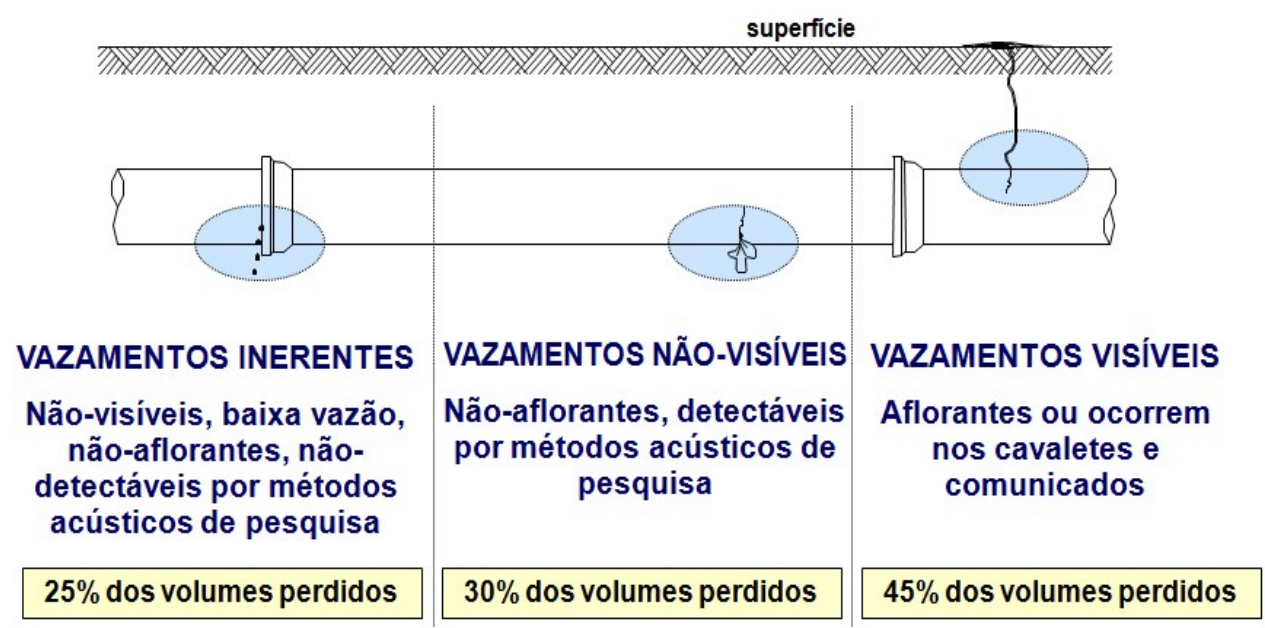

Como exemplo é citado aqui o caso ocorrido no bairro do lbura, situado na RMR, onde estudos desenvolvidos pelo Grupo de Engenharia Geotécnica de Encostas, Planícies e Desastres (GEGEP), realizou análise de estabilidade de uma determinada encosta. O local foi escolhido em conjunto com a Defesa Civil do Município e a Universidade Federal de Pernambuco, devido à ocorrência de deslizamento de solo que provocou a morte de duas pessoas. A análise foi realizada através da determinação do Fator de Segurança da encosta na sua condição natural e na condição de saturação do solo, situação essa ocorrida devido ao vazamento de tubulação clandestina existente no local de estudo. O vazamento da referida tubulação foi relatada por moradores locais.

Para a análise de estabilidade da encosta foi realizada campanha geotécnica para realização de sondagens que possibilitaram o traçado do perfil geotécnico da região. Foram também realizadas coletas de amostras de solos 
Revista Científica do Corpo de Bombeiros Militar de Pernambuco

Seção 1 - Artigos Técnico Científicos

Artigo publicado no Vol.04 №09 - Edição de JAN a JUN 2018 - ISSN 2359-4837(online)

Versão on-line disponível em: http://www.revistaflammae.com.

a diferentes profundidades, sendo essas amostras submetidas a ensaios de caracterização, resistência e permeabilidade. Foi realizado ainda levantamento topográfico que possibilitou o traçado da geometria da encosta, também essencial nas análises.

\subsection{Análises de estabilidade}

As análises de estabilidade foram realizadas com o auxílio de programa SLOPE / W da GEO-SLOPE, considerando a teoria do equilíbrio limite (COUTINHO et al. 2006).

A superfície de ruptura coincide com a superfície determinada após a ruptura de acordo com dados topográficos, além de informações obtidas através de técnicos da Defesa Civil e moradores locais. Os parâmetros de resistência do solo foram obtidos através de ensaios de resistência ao cisalhamento em amostras indeformadas, coletadas no local. As amostras indeformadas foram também utilizadas nos ensaios de sucção e permeabilidade do solo.

Para a análise da ruptura foi utilizado o método de Bishop Modificado com a superfície de ruptura e fator de segurança para a situação de solo na umidade natural e para a situação mais crítica com saturação do solo, sendo então adotados parâmetros para o solo inundado e pressão neutra $u=0$ (COUTINHO et al. 2006).

Coutinho et al. (2006) explica que a situação crítica com solo saturado é baseada na condição ocorrida na ocasião da ruptura: com ocorrência de fortes chuvas e com ocorrência de vazamento de tubulação clandestina de água. A Tabela 1 apresenta o resumo das características do solo e dos parâmetros de resistência utilizados na análise do solo saturado. 
Revista Científica do Corpo de Bombeiros Militar de Pernambuco Seção 1 - Artigos Técnico Científicos

Artigo publicado no Vol.04 №09 - Edição de JAN a JUN 2018 - ISSN 2359-4837(online)

Versão on-line disponível em: http://www.revistaflammae.com.

Tabela 1. Características e parâmetros de resistência do solo saturado

\begin{tabular}{llccll}
\hline Camada & Tipode solo & Prof. $(\mathrm{m})$ & $\gamma\left(\mathrm{kN} / \mathrm{m}^{3}\right)$ & $\mathrm{C}^{\prime} \mathrm{CD}(\mathrm{kPa})$ & $\varphi^{\prime} \mathrm{CD}\left({ }^{0}\right)$ \\
\hline 1 & $\mathrm{SC}$ & 0,0 a 3,30 & 17,1 & 0 & $36,1^{0}$ \\
\hline 2 & $\mathrm{CL}$ & 3,30 a 3,60 & 20,5 & 0 & $29,0^{0}$ \\
\hline 3 & $\mathrm{ML}$ & 3,60 a 4,00 & 18,0 & 8,88 & $29,4^{0}$
\end{tabular}

Fonte: COUTINHO et al., 2006.

Para a análise de estabilidade da encosta na condição do solo com unidade natural, foram utilizados os parêmatros de resistência apresentados na Tabela 2.

Tabela 2. Características e parâmetros de resistência do solo com umidade natural

\begin{tabular}{rrccll}
\hline Camada & Tipo de solo & Prof. $(\mathrm{m})$ & $\gamma\left(\mathrm{kN} / \mathrm{m}^{3}\right)$ & $\mathrm{c}^{\prime}{ }_{\mathrm{CD}}(\mathrm{kPa})$ & $\varphi^{\prime}{ }_{\mathrm{CD}}\left({ }^{0}\right)$ \\
\hline 1 & $\mathrm{SC}$ & 0,0 a 3,30 & 17,1 & 20,28 & $31,8^{0}$ \\
\hline 2 & $\mathrm{CL}$ & 3,30 a 3,60 & 20,5 & 43,57 & $43,7^{0}$ \\
\hline 3 & $\mathrm{ML}$ & 3,60 a 4,00 & 18,0 & 20,0 & $30,0^{\circ}$ \\
\hline
\end{tabular}

Fonte: Coutinho et al., 2006.

As Figuras 2 e 3 apresentam a análise de ruptura para a condição crítica (solo inundado) e condição natural, respectivamente. 
Revista Científica do Corpo de Bombeiros Militar de Pernambuco

Seção 1 - Artigos Técnico Científicos

Artigo publicado no Vol.04 NN09 - Edição de JAN a JUN 2018 - ISSN 2359-4837(online)

Versão on-line disponível em: http://www.revistaflammae.com.

Figura 2. Análise de ruptura na condição inundada

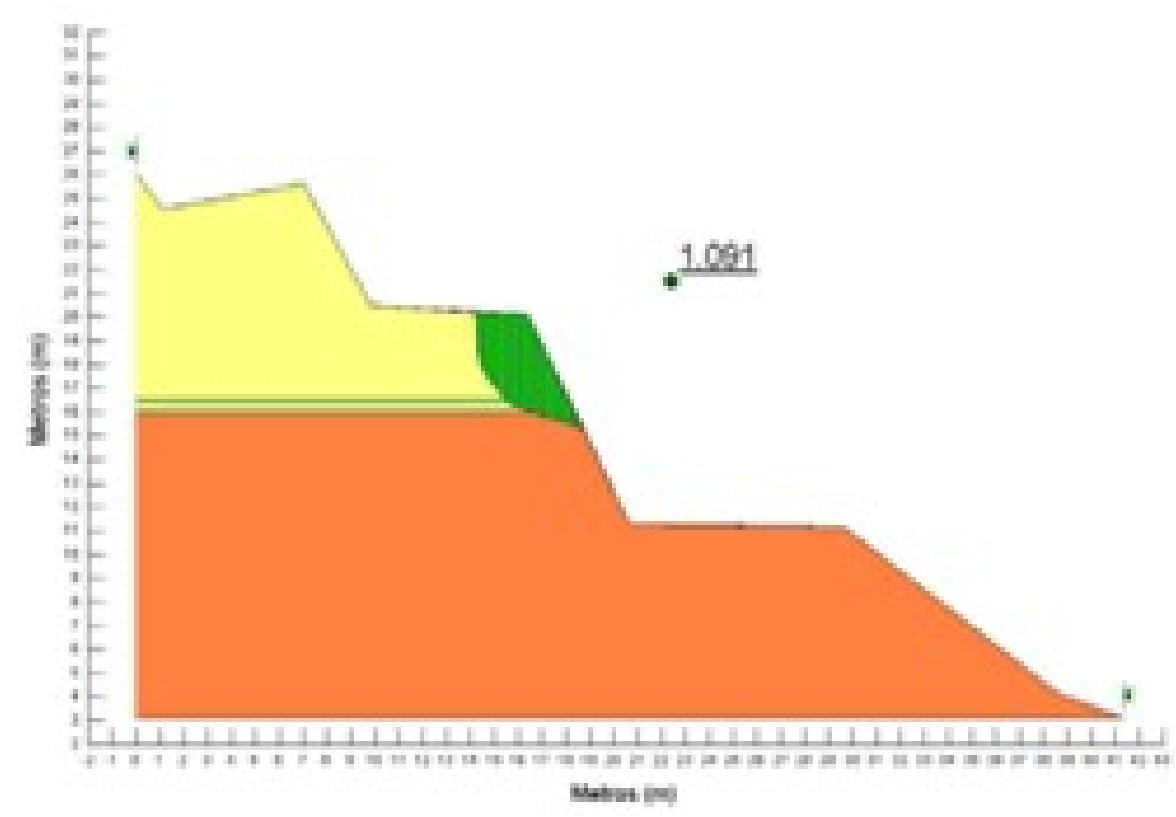

Fonte: COUTINHO et al., 2006.

Figura 3. Análise de ruptura para os solos na condição de umidade natural

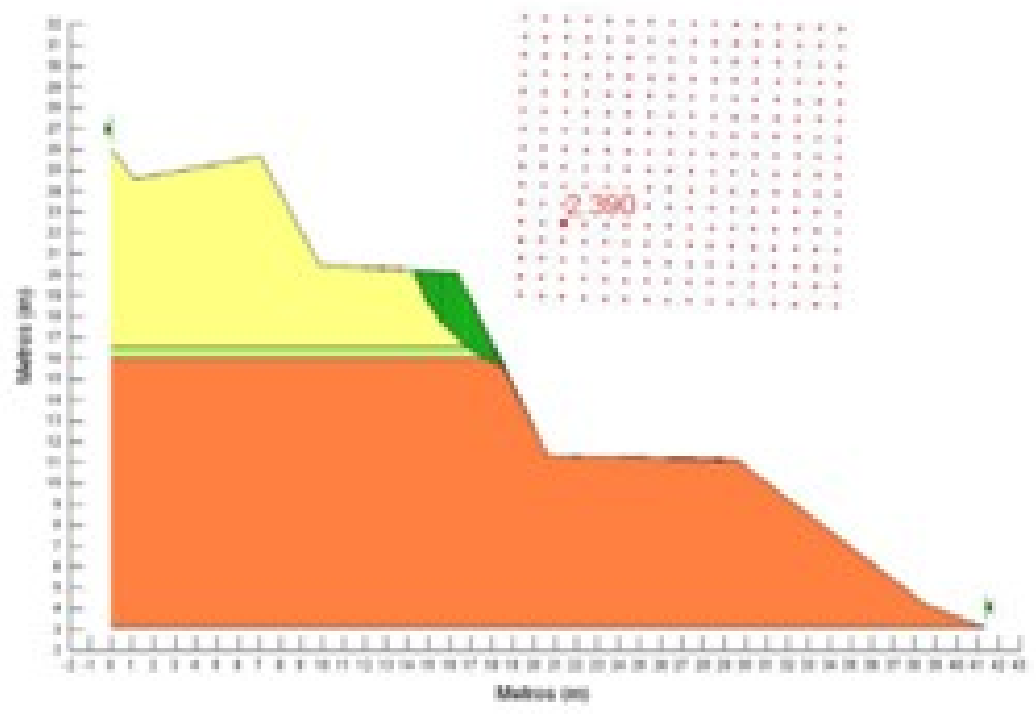

Fonte: COUTINHO et al., 2006. 
Revista Científica do Corpo de Bombeiros Militar de Pernambuco

Seção 1 - Artigos Técnico Científicos

Artigo publicado no Vol.04 №09 - Edição de JAN a JUN 2018 - ISSN 2359-4837(online)

Versão on-line disponível em: http://www.revistaflammae.com.

As análises realizadas nas diferentes condições, reflete a significativa redução de estabilidade quando ocorre a saturação do solo, demonstrada pela redução do Fator de Segurança de 2,390 na condição de umidade natural, para 1,091 na condição de solo saturado (COUTINHO et al. 2006). Importante destacar que o Fator de Segurança igual a um representa a ruptura, corroborando assim com o fato ocorrido em campo.

Após a ruptura ocorrida, a encosta assumiu uma nova geometria, chamada de situação atual, sendo assim, foram então realizadas novas análises. A Tabela 3 apresenta o resumo dos resultados obtidos para as análises realizadas para a geometria da encosta antes e após a ruptura, bem como para os parâmetros de resistência considerados na condição do solo inundado e com umidade natural.

Tabela 3. Síntese das análises de estabilidade

\begin{tabular}{llr}
\hline \multirow{2}{*}{ Situação } & \multicolumn{2}{c}{ Parâmetros } \\
\cline { 2 - 3 } & Solo Saturado & \multicolumn{2}{c}{ Umidades naturais } \\
\hline Análise da ruptura & $\mathrm{FS}=1,091$ & $\mathrm{FS}=2,390$ \\
\hline Situação atual & $\mathrm{FS}=1,014$ & $\mathrm{FS}=3,116$ \\
\hline
\end{tabular}

Fonte: Coutinho et al., 2006.

No exemplo de pesquisa apresentado, Coutinho et al. (2006) comenta que é clara a forte influência da redução da sucção do solo, refletindo assim na instabilização da encosta estudada. Santana (2006) comenta ainda que apesar de comprovar a grande influência negativa da presença da água na encosta, é impossível saber qual parcela de contribuição a água desempenhou maior influência na ruptura ocorrida. 
Revista Científica do Corpo de Bombeiros Militar de Pernambuco

Seção 1 - Artigos Técnico Científicos

Artigo publicado no Vol.04 NN09 - Edição de JAN a JUN 2018 - ISSN 2359-4837(online)

Versão on-line disponível em: $\underline{\text { http://www.revistaflammae.com. }}$

\section{ESGOTAMENTO SANITÁRIO}

Muitas vezes o esgotamento sanitário é entendido pela população como sendo o saneamento básico, no entanto, importante diferenciar, que o esgotamento sanitário é apenas uma parcela do conjunto de atividades que englobam o saneamento básico, de acordo com a Lei 11.445/2007. E ainda, de acordo com a Norma Brasileira - NBR 9648:1986 - Estudos de concepção de sistemas de esgoto, o esgotamento sanitário é o despejo líquido constituído de esgotos doméstico e industrial, água de infiltração e a contribuição pluvial parasitária.

A ausência de esgotamento sanitário nas encostas ocupadas de forma desordenada conduz ao lançamento diário de águas servidas na superfície do solo, propiciando assim a formação de processo erosivo que constantemente desagrega a superfície do terreno. Associado a isto, a construção de fossas sanitárias, que é muito comum em áreas que não possuem sistema de coleta de esgoto, também contribui negativamente. Pois as fossas são geralmente construídas sem nenhum tipo de proteção impermeabilizante, provocando a contaminação do lençol freático. E além disso, a existência desta forma rudimentar de esgoto propicia a formação de bolsões de solo saturado prejudicando as condições de estabilidade dos taludes, conforme mostra o esquema apresentado na Figura 4. 


\section{Revista FLAMMAE}

Revista Científica do Corpo de Bombeiros Militar de Pernambuco

Seção 1 - Artigos Técnico Científicos

Artigo publicado no Vol.04 №09 - Edição de JAN a JUN 2018 - ISSN 2359-4837(online)

Versão on-line disponível em: http://www.revistaflammae.com.

Figura 4. Influência das fossas rústicas na estabilidade do talude.

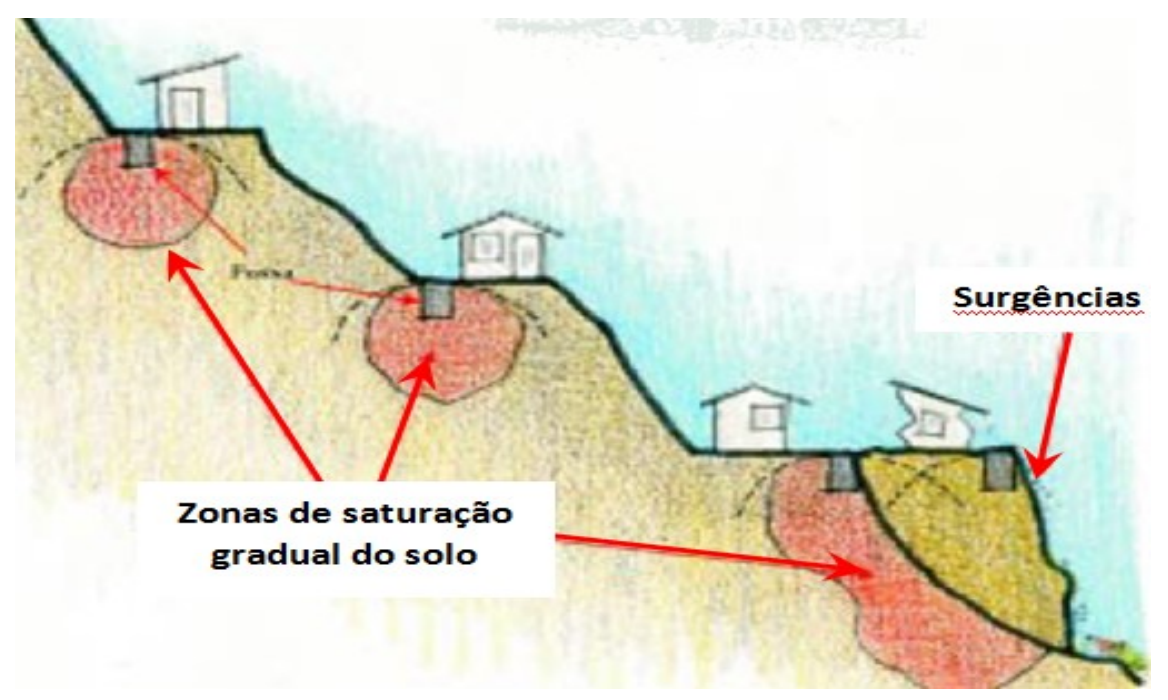

Fonte: Alheiros et al. (2003)

Em visitas a áreas de risco realizados na Região Metropolitana do Recife é muito comum encontrar lançamento de águas servidas em canaletas construídas de forma improvisada pelos próprios moradores. Nos dias de chuva, também não existe local adequado para a água precipitada. A Figura 5 demonstra a inexistência de elementos de esgotamento sanitário e de drenagem.

Figura 5. Drenagem improvisada para destino de águas servidas e pluviais.

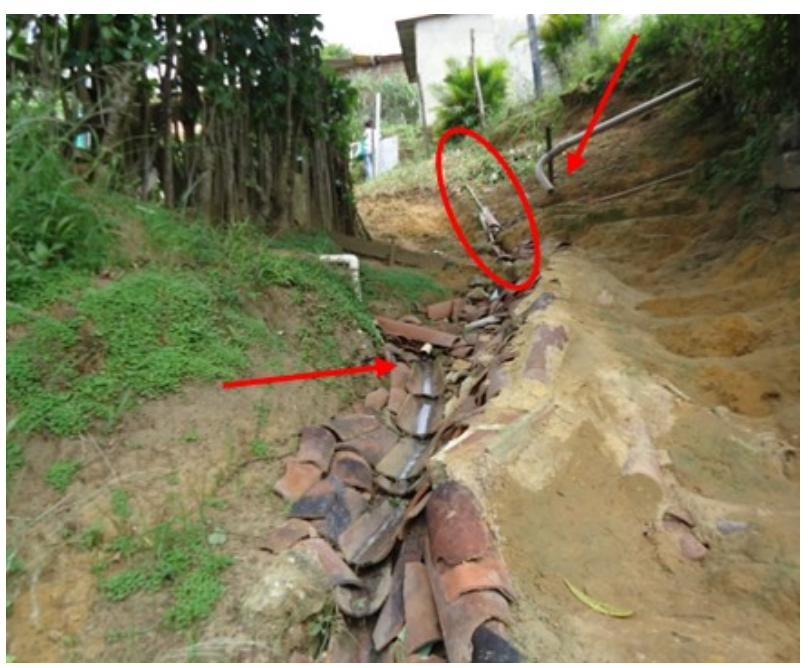

Fonte: SILVA (2016) 
Revista Científica do Corpo de Bombeiros Militar de Pernambuco

Seção 1 - Artigos Técnico Científicos

Artigo publicado no Vol.04 №09 - Edição de JAN a JUN 2018 - ISSN 2359-4837(online)

Versão on-line disponível em: http://www.revistaflammae.com.

A inexistência de elementos de drenagem e esgotamento sanitário na encosta apresentada indica local propício à ocorrência de erosão linear. A Figura 6 apresenta a condição encontrada em campo alguns metros a jusante do escoamento apresentado. Importante ainda destacar que a população local sofre também com dificuldades de locomoção e risco de propagação de doenças.

Figura 6. Formação de ravina de erosão formada pelo lançamento inadequado de água servida

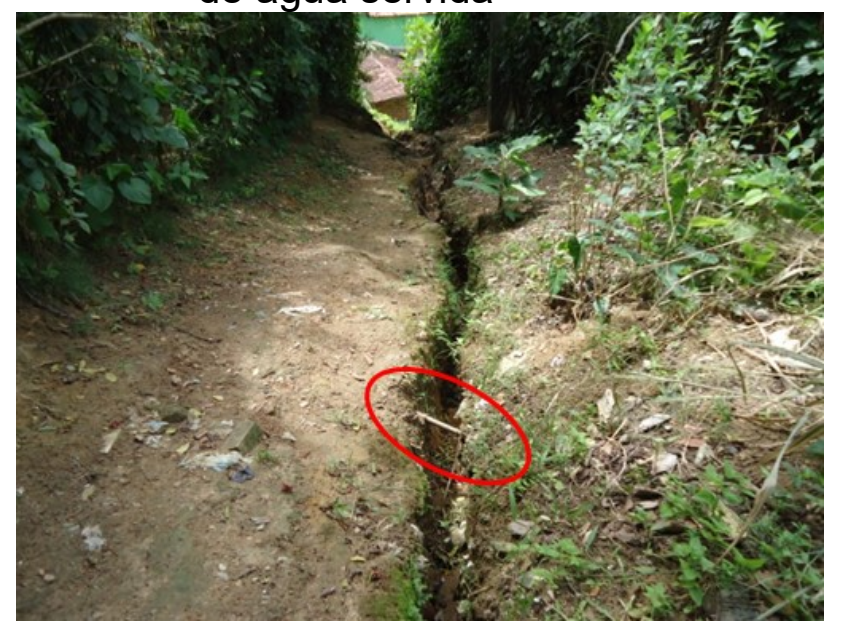

Fonte: SILVA , 2016

As intervenções em saneamento básico nos morros necessitam de um planejamento inicial que considere bacias e microbacias de esgotamento como unidades de coleta independentes e de tratamento descentralizado, podendo ter vida própria para sua operação, de forma a permitir que sua implantação se faça de forma parcial, por etapas.

A estruturação de sistemas ou microssistemas de esgotamento sanitário deverá compreender as soluções internas individuais de cada moradia e, a rede de coleta e destinação final dos esgotos. Este é um planejamento que envolve investimentos elevados visto à necessidade primária de instalações 
Revista Científica do Corpo de Bombeiros Militar de Pernambuco

Seção 1 - Artigos Técnico Científicos

Artigo publicado no Vol.04 NN09 - Edição de JAN a JUN 2018 - ISSN 2359-4837(online)

Versão on-line disponível em: http://www.revistaflammae.com.

sanitárias mínimas para os moradores, e permitindo sua interligação a um completo sistema de esgotamento sanitário.

\section{LIMPEZA URBANA}

Inserida dentro do conjunto de ações que compõem o saneamento básico, a limpeza urbana é vista não só como questão de saúde e bem estar público, mas também como ponto importante para redução do risco de deslizamentos, erosão e inundação, desastres esses tão frequentes nos grandes centros urbanos brasileiros.

A limpeza urbana é fator importante a ser discutido e melhorado com o envolvimento do Município e da comunidade. Para enfrentar a situação, administradores e população devem começar a discutir objetivamente $\mathrm{o}$ problema, conscientes de suas responsabilidades e de que o bom funcionamento do serviço de limpeza urbana é imprescindível para atingir os objetivos desejados na redução do risco nas comunidades.

$\mathrm{O}$ acúmulo de lixo aumenta o peso na encosta e provoca deslizamentos. $E$ além disso, entope valas e é capaz de causa enchentes.

Um dos aspectos maléficos da ausência de limpeza urbana é o caso do lixo acumulado às margens de cursos d'água ou de canais de drenagem e em encostas, podendo provocar inundações, assoreamento de cursos d'água e o deslizamento de encostas.

O lixo lançado em encostas comporta-se de forma a reter água, elevando assim o seu peso sobre o talude, provocando a sua desestabilização. A Foto 7 apresenta um caso em que uma encosta com acúmulo de lixo deslizou provocando a morte de duas pessoas, o fato foi publicado no Jornal do Commercio, em sua edição do dia 29/06/2015. A obstrução de elementos de drenagem devido ao lixo prejudica a correta condução da água provocando casos de inundação e maior infiltração no solo. Durante a decomposição da matéria orgânica é produzido o chorume que infiltra no solo, provocando a 
Revista Científica do Corpo de Bombeiros Militar de Pernambuco

Seção 1 - Artigos Técnico Científicos

Artigo publicado no Vol.04 №09 - Edição de JAN a JUN 2018 - ISSN 2359-4837(online)

Versão on-line disponível em: http://www.revistaflammae.com.

contaminação do lençol freático. Ou seja, a presença do lixo conduz a uma série de problemas para a comunidade, colocando em risco a qualidade de vida, a saúde e até a vida da população.

Figura 7. Deslizamento de encosta com acúmulo de lixo. Local: Bomba do Hemetério-Recife

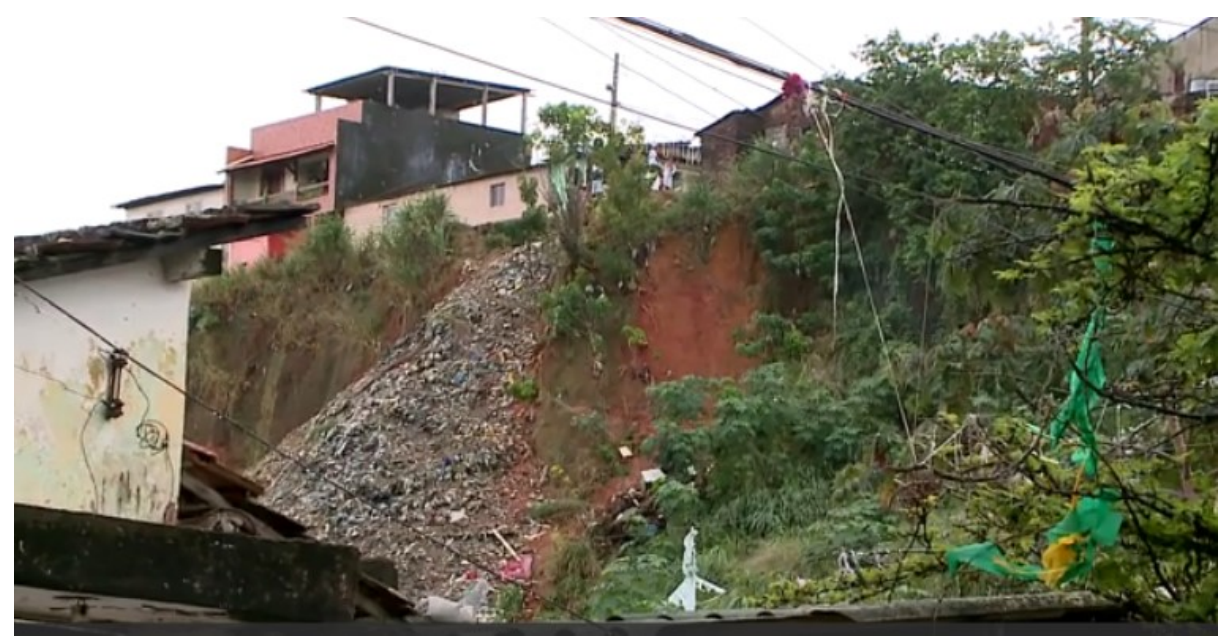

. Fonte: Jornal do Comercio (publicado em 29/06/2015)

Esta é uma situação comum em muitas cidades brasileiras: a população de renda mais baixa ocupa morros, mangues, e áreas de difícil acesso à coleta do lixo. Os veículos empregados normalmente na limpeza urbana costumam ser impróprios para operar nessas áreas. A consequência imediata é o despejo do lixo produzido em encostas, valas, cursos de água.

A intervenção de limpeza urbana na remoção de lixos e entulhos de encostas, elementos de drenagem e vias de circulação, reduzem o risco de deslizamentos e inundações. É de grande importância também a conscientização da população de forma a evitar a ocorrências destes registros.

Para enfrentar o problema, costuma-se escolher determinados locais para a acumulação dos resíduos produzidos pelos moradores. São os chamados "pontos de lixo", que precisam ser acessíveis aos veículos coletores 
Revista Científica do Corpo de Bombeiros Militar de Pernambuco Seção 1 - Artigos Técnico Científicos

Artigo publicado no Vol.04 №09 - Edição de JAN a JUN 2018 - ISSN 2359-4837(online)

Versão on-line disponível em: http://www.revistaflammae.com.

e devem ser providos de algum tipo de acondicionamento. Em áreas de difícil acesso, como ocorre em comunidades desenvolvidas de forma desordenada, é recomendada a coleta de lixo feita de forma manual pelo Município, sendo assim necessário o uso de equipamentos de dimensões reduzidas que permitam fácil mobilidade no interior da comunidade. Alheiros et al. (2003) apresenta na Figura 8 um exemplo desse tipo de coleta em comunidade do Recife.

Figura 8. Sistema de Coleta de Lixo em Banguê com garis comunitários.

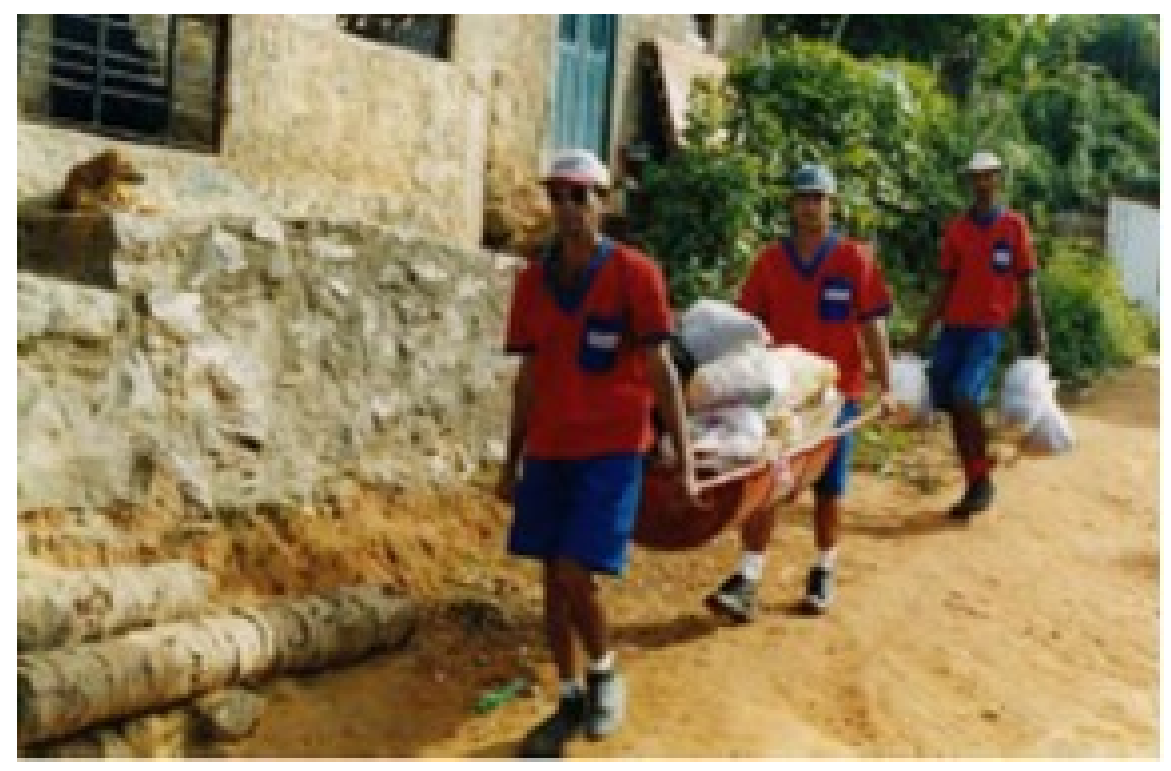

Fonte Alheiros et al., 2003.

\section{DRENAGEM URBANA}

De acordo com Alheiros et al. (2003) a água é o principal agente deflagrador dos movimentos gravitacionais de massa e de transporte de massa (erosão). Este fato é fácil de comprovar ao perceber que o período chuvoso é representativo nas ocorrências de deslizamentos. A ausência de elementos de drenagem, esgotamento sanitário e as precárias redes de abastecimento 
Revista Científica do Corpo de Bombeiros Militar de Pernambuco

Seção 1 - Artigos Técnico Científicos

Artigo publicado no Vol.04 N09 - Edição de JAN a JUN 2018 - ISSN 2359-4837(online)

Versão on-line disponível em: http://www.revistaflammae.com.

clandestino contribuem com o constante lançamento de água sobre os taludes de áreas ocupadas.

O caminho preferencial do escoamento tem o relevo como determinante do seu traçado. Assim, a concepção do sistema de drenagem tem sua melhor eficiência quando se leva em consideração as características topográficas locais. Os elementos do sistema de drenagem são classificados em função de suas dimensões em microdrenagem ou macrodrenagem.

Silva (2010) descreve que o sistema de drenagem em encostas ocupadas pode ser dividido em drenagem superficial, drenagem subsuperficial ou profunda, e drenagem de estruturas de contenção.

Em encostas ocupadas o desencadeamento dos movimentos de massa é comum, em decorrência das deficiências de capacidade e funcionamento, ou mesmo inexistência de um sistema de drenagem superficial adequado nas residências, ou ainda de escoamentos irregulares que se concentram aleatoriamente.

Alheiros et al. (2003) colocam a obras de drenagem como importante aliado às obras de contenção e proteção superficial das encostas, os autores comentam que, como o revestimento superficial tem a função de reduzir o volume da água de infiltração, fazendo, portanto, com que aumente o volume das águas de escoamento superficial, faz-se necessária a elaboração de projeto que considere a encosta no contexto da sua microbacia, buscando resolver o escoamento superficial com obras complementares de um sistema de microdrenagem, com canaletas e dissipadores de energia compatíveis com as vazões e os caminhos naturais da água.

$\mathrm{Na}$ grande maioria dos casos, a estabilização de taludes naturais ou de corte têm nas soluções de revestimento e drenagem as respostas mais eficientes, com menor tempo de execução e menor custo.

As obras de contenção precisam de elementos de drenagem que aumentem sua eficiência e garantam a durabilidade da obra, a Figura 9 


\section{Revista FLAMMAE}

Revista Científica do Corpo de Bombeiros Militar de Pernambuco

Seção 1 - Artigos Técnico Científicos

Artigo publicado no Vol.04 №09 - Edição de JAN a JUN 2018 - ISSN 2359-4837(online)

Versão on-line disponível em: http://www.revistaflammae.com.

apresenta um exemplo de microdrenagem com o uso de canaletas e barbacã (elemento de drenagem interna do solo) a ser aplicado em muros de arrimo.

Figura 9. Esquema do sistema construtivo de muro de alvenaria de pedra.

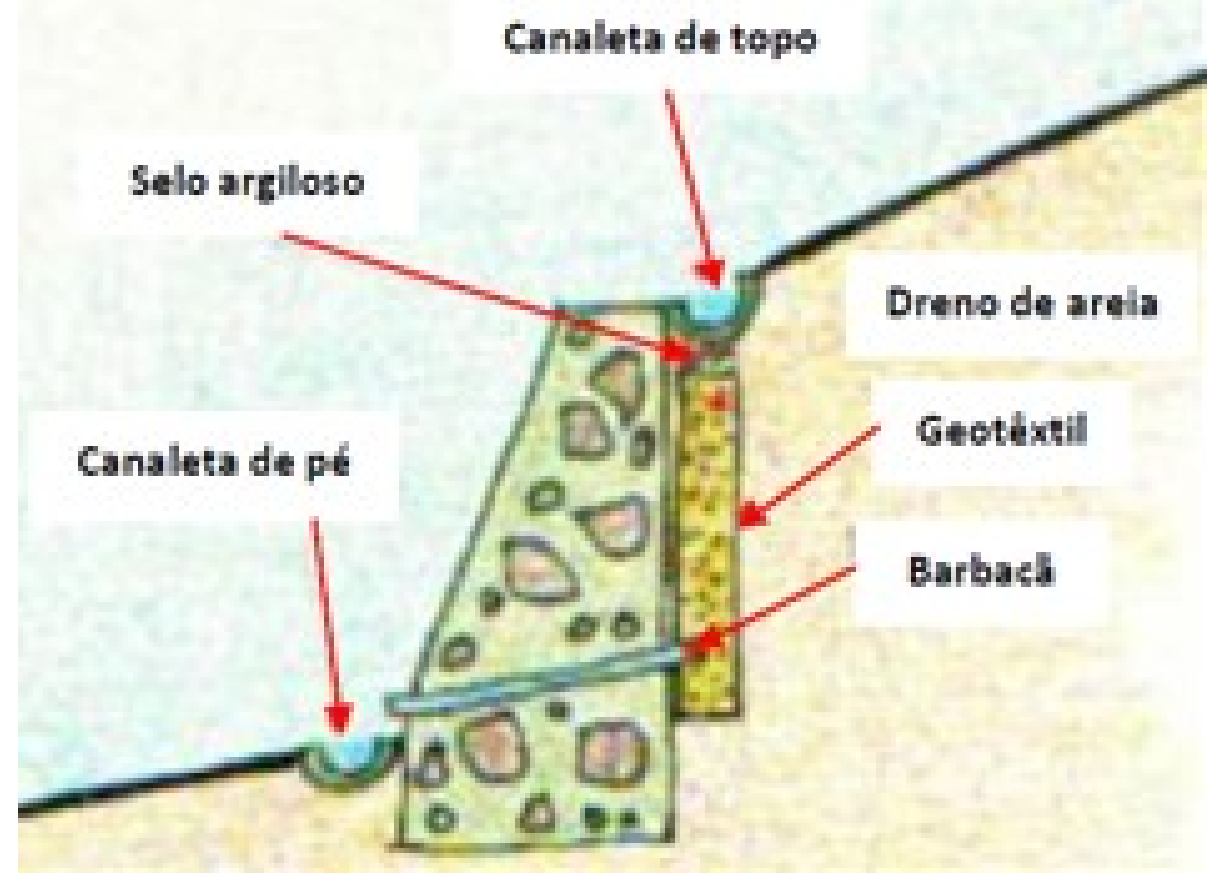

Fonte Alheiros et al. (2003).

No Município de Olinda, localizado na Região Metropolitana do Recife, obras de drenagem do Riacho Ouro Preto e Canal do Fragoso composta de revestimento e retificação do canal busca aumentar a velocidade de fluidez da água corrente, no entanto a modificação na calha do rio tem causado inundação nas áreas de planície devido à mudanaça no padrão de drenagem, que regou a redução do comprimento do canal pós alargamento, aprofundamento e retificação, e ainda promoveu a diminuição de rugosidades do leito e aumento do gradiente.

A Figura 10 apresenta caso de inundação ao longo do curso do Riacho Ouro Preto, após a ocorrência de fortes chuvas. O fato ocorreu ainda durante a cosntrução do canal, o que agravou o impacto da inundação. 


\section{Revista FLAMMAE}

Revista Científica do Corpo de Bombeiros Militar de Pernambuco

Seção 1 - Artigos Técnico Científicos

Artigo publicado no Vol.04 №09 - Edição de JAN a JUN 2018 - ISSN 2359-4837(online)

Versão on-line disponível em: http://www.revistaflammae.com.

Figura 10. Transbordamento do Canal do Fragoso, Município de Olinda - PE.

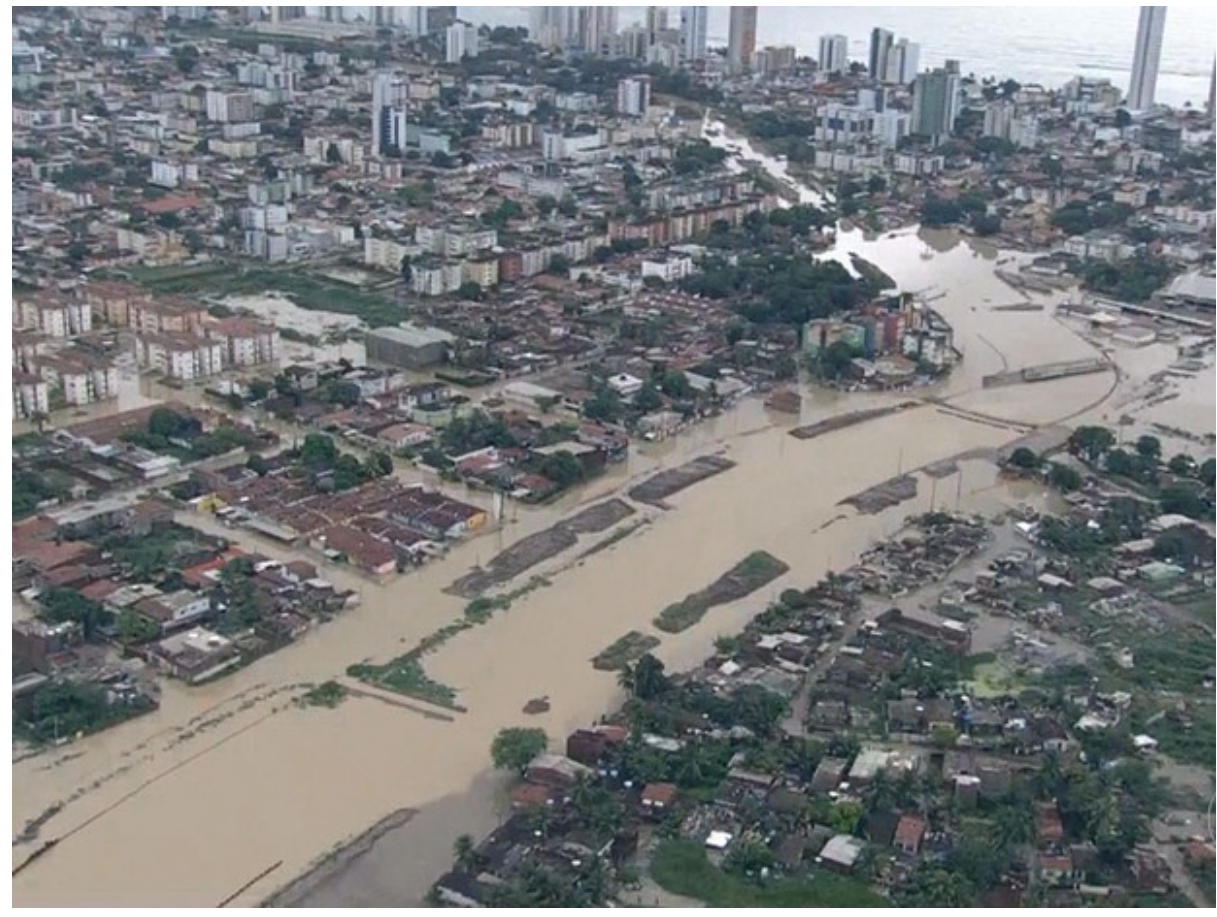

Fonte: site http://g1.globo.com/pe

\section{CONCLUSÕES E RECOMENDAÇÕES}

A ação antrópica atunado de forma negativa no meio ambiente, conduz a impactos que são determinantes para a ocorrência do risco de deslizamento, erosão e inundação na áreas ocupadas desordenadamente. Logo após a instalação dessas ocupações, o sanemaento apresenta-se como uma necessidade imediadta e assim, de forma não planejada, a população improvisa seu saneamento fazendo-o de forma desrepeitosa com o ambiente. O resultado disso é a ocorrência de frequentes situações de risco à população, principalmente nos períodos chuvosos.

Como demonstrado ao longo desse trabalho, a presença adequada de um sistema de saneamento, englobando $\mathrm{o}$ abastecimento de água, 0 esgotamento sanitário, a limpeza e a drenagem urbana, impacta diretamente 
Revista Científica do Corpo de Bombeiros Militar de Pernambuco Seção 1 - Artigos Técnico Científicos

Artigo publicado no Vol.04 №09 - Edição de JAN a JUN 2018 - ISSN 2359-4837(online)

Versão on-line disponível em: http://www.revistaflammae.com.

na redução do risco de desastres.

Para amenizar os riscos nas áreas já ocupadas de forma desordenadas, observa-se a necessidade da implantação de sistemas adequados de saneamento, como também o desenvolvimento de trabalhos de conscientização da população no tocante à eliminação de ações prejudiciais ao risco, tais como: lançamento inadequado do lixo; construção de valas de drenagem inadequadas; instalação de fossas rústicas e implantação de tubulações de água clandestinas sem qualquer proteção. Nas situações mais críticas, com a presença de risco iminente, é necessário ainda a intervenção imediata da Defesa Civil Municipal no sentido de remoção das moradias dessas áreas e condução das famílias para áreas seguras.

A ausência de saneamento nas áreas ocupadas desordenadamente conduz não só ao risco à saúde, mas também ao risco de acidentes com danos às pessoas e às suas moradias.

\section{REFERÊNCIAS}

ABNT NBR 9648:1986. Estudo de concepção de sistemas de esgoto sanitário - Procedimento. Associação Brasileira de Normas Técnicas (ABNT), Norma Brasileira Regulamentadora (NBR).

ALHEIIROS, M. M. SOUZA, M. A. A., BITOUN J., MEDEIROS, S.M. G. M., AMORIM JÚNIOR, W. A. Manual de ocupação dos morros da Região Metropolitana do Recife. FIDEM, Recife - PE, 2003.

BANDEIRA, A. P.. Mapa de risco de erosão e escorregamento das encostas com ocupações desordenadas no município de Camaragibe-PE. Recife. Dissertação de Mestrado em Engenharia Civil. UFPE, Recife-PE, 2003. 
Revista Científica do Corpo de Bombeiros Militar de Pernambuco

Seção 1 - Artigos Técnico Científicos

Artigo publicado no Vol.04 N009 - Edição de JAN a JUN 2018 - ISSN 2359-4837(online)

Versão on-line disponível em: http://www.revistaflammae.com.

BRASIL, Lei 11.445 de 05 de janeiro de 2007. Disponível em http://www.planalto.gov.br/ccivil_03/_ato2007-2010/2007/lei//11445.htm Acesso em: 16 jul 17.

COUTINHO, R.Q., GUSMÃO, A.D. , SANTANA, R.G. $2^{\circ}$ Relatório - Parecer Técnico. Universidade Federal de Pernambuco, Recife-PE, 2006.

G1 Portal de Notícias. Transbordamento do Canal do Fragoso deixa centenas de casas inundadas em Olinda Data do noticiário: 30 de maio de 2016. Disponível em: http://g1.globo.com/pe, Acesso em 23mai17.

JC - Jornal do Commercio. : Barreira desliza e mata 2 pessoas na Bomba do Hemetério Noticiário Data do noticiário: 29 de junho de 2015. Disponível em: htt://jconline.ne10.uol.com.br . Acesso em 29jun15.

SANTANA, R. G. Análises de Soluções de engenharia para estabilização de encostas ocupadas na Região Metropolitana do Recife-PE. Estudo de caso: Ruptura ocorrida em encosta com ocupação desordenada na UR-2, Ibura. Dissertação de Mestrado em Engenharia Civil. UFPE, Recife - PE, 2006.

SILVA, R.R. Proposta para estabilização de uma encosta ocupada em Camaragibe-PE com consideração de um tratamento global. Dissertação de Mestrado, Universidade Federal de Pernambuco. CTG. Recife, 2010.

SILVA, D. J. (2016). Mapa de risco de deslizamento e erosão em encostas com ocupações desordenadas no Município de Abreu e Lima - PE. Dissertação de Mestrado, Universidade Federal de Pernambuco. CTG. Recife, 2016. 


\section{Revista FLAMMAE}

Revista Científica do Corpo de Bombeiros Militar de Pernambuco Seção 1 - Artigos Técnico Científicos

Artigo publicado no Vol.04 N09 - Edição de JAN a JUN 2018 - ISSN 2359-4837(online)

Versão on-line disponível em: http://www.revistaflammae.com.

OMS - Organização Mundial da Saúde. Saneamento no Brasil. Disponível em: http://www.tratabrasil.org.br/saneamento-no-brasil-bakup Acesso em: 09mai17. 